\title{
Distributed Leadership in Secondary Schools: Possibilities and Impediments in Bangladesh
}

\author{
Abu Nayeem Mohammad Salahuddin*
}

\section{Introduction}

Effective school leadership is a basic tenet for successful school since the outcome of a school depends on the quality of leadership. As a current popular form of leadership, distributed leadership focuses on the leadership of all team members in a school. Research shows that successful leadership depends on the context and time of a school. This paper tries to conceptualize distributed leadership in Bangladesh context during the time of their education restructuring. Though distributed leadership is seldom discussed and operated in developing countries, it advocates the implementation in those contexts due to the continuous success of it in the developed world. Hence, this conceptual paper discusses the possibilities and the potential problems in relation to implement this leadership form for the reforming education sector of Bangladesh. Prior to this, the theoretical background of distributed leadership has been considered in this article. To develop and deliver distributed leadership in Bangladesh, this paper suggests for initiating training programme for head teachers which should focus on long term positive change in education.

\section{What is Distributed Leadership?}

Distributed leadership is a relatively recent concept of educational leadership which focuses not only on the leadership of the head of a school but also on that of other team members. New theories for leadership, such as distributed leadership, are produced in the education field, often with little empirical inquiry through this relatively brief period of time. As Harris (2008: 172) explains,

\footnotetext{
* Lecturer, Institute of Education and Research, University of Dhaka.
} 


\begin{abstract}
New leadership theories have been formulated, packaged and successfully sold to schools without adequate scrutiny or testing. There are many leadership "war stories" in the educational world that offer important insights about individual approaches to leading but tell us little about the practice of leadership often reducing leadership to "silver bullet" advice.
\end{abstract}

However, the emergence of new theories cannot be overlooked as the focus of leadership changes due to the necessity for effective leadership.

Effective leadership is a basic principle of successful schools. School outcomes depend on the quality of leadership, as Bush and Jackson (2002:417) imply that, "The relationship between high quality school leadership and educational outcomes is well documented. Generations of research on school effectiveness show that excellent leadership is invariably one of the main factors in high performing schools". The connection between school effectiveness and quality of leadership in different contexts of the world has been identified and explored by various researchers. Much of the current research focuses on the concept of distributed leadership, as Bush and Jackson (2002: 417) state, "The focus of the literature is on the leadership role of the principal but there is increasing interest in notions of 'dispersed' or 'distributed' leadership".

Distributed leadership is an emerging concept in the field of educational leadership. However, the concept and usage of different leadership styles is little understood in developing countries like Bangladesh. The school leaders seldom think about how a leadership style would be beneficial for a school and why they should use it. Harris (2002) identifies distributing leadership as a factor of success for a leader in a challenging context depending on the particular situation and context of the school. As Bangladesh is now facing the challenge of reformation in secondary education sector, it could consider distributed leadership as a means to achieve that. This type of leadership encompasses an achievable and sustainable practice of school leadership that evolves to a wider distribution of essential leadership responsibilities across a school (Elmore 2000). It is a leadership concept and model that could 
break the isolation of traditional structural leadership, improving student achievement and making leadership more collaborative in Bangladesh.

Though distributed leadership is a burning topic in the educational leadership literature, it remains an unclear and divergent concept, lacking a coherent conceptual base (Harris 2005; Spillane 2006). This article tries to clarify the concept of distributed leadership and identify possibilities and barriers to be overcome for such leadership development in secondary education in Bangladesh.

\section{Secondary Education in Bangladesh}

Education in Bangladesh is divided into three major stages: primary, secondary and higher education. Primary education is 5 years, secondary education is 7 years with three sub-stages: 3 years of junior secondary, 2 years of secondary and 2 years of higher secondary (Bangladesh Bureau of Educational Information and Statistics [BANBEIS] 2010). At secondary level, most of the schools are run privately through government financial support. The schools generally provide co-education though a minority offers single sex education. The secondary education is administered by the Ministry of Education and its line authority. "The Ministry of Education is concerned with policy formulation, planning, monitoring and evaluation of the post-primary education sector" (BANBEIS 2007). Secondary education administration in the schools is operated by the Head Teachers. School administration is shaped by the traditional and historical heritage of the prevailing colonial system (Thornton 2006).

There are two key leadership positions in every secondary school. To do the executive job in a school the head teacher has the power and an assistant head teacher is responsible for line authority. They hold the formal leadership roles, and are responsible for the development and improvement of the school. School quality is measured by the results of public examinations. The teachers' remuneration and school facilities are of concern when the head teachers try to improve student learning in the schools (Thornton 2006). Most of the head teachers have to lead in challenging contexts due to teacher- student ratio, physical facilities, the economy and the socio-political environment. To move schools 
forward, given this situation and limited resources, it is demanding and challenging to explore the practice of distributed leadership in the problematic milieu of secondary education in Bangladesh.

\section{Concepts of Distributed Leadership}

Successful leaders have to work inside and outside the boundaries of their school context. As there are ambiguities about the activities which may actually be considered leadership, it is difficult to sketch the boundaries of a leaders' work (Mayrowetz 2008). Leaders may work alone or collaboratively. Duignan (2006: 105) voices a concern, "Many educational leaders leave themselves isolated and alone, taking primary responsibility for the leadership of their school. This constitutes a very narrow view of leadership and ignores the leadership talents of teachers, students and other community stakeholders". Leadership in education requires a culture of sharing of energy, commitment and contribution of all who work there to be successful with their leadership responsibilities. In most organisations leadership has been seen as based on the authority or power given by the head teacher position positional leadership. However, schools, as complex social organizations, depend on collaborative work to face challenges. As Elmore (2000: 15) voices,

Leadership of schools is beyond the capacity of any one person, or of those in formal leadership positions only, and should be distributed to engage the 'contours of expertise' in the school community, creating a culture that provides coherence, guidance and direction for teaching, learning and leadership.

Distributed leadership acknowledges a broader perspective of leadership activities than just the leadership of school principals. A distributed perspective in school frames leadership practice as a product of interaction among leaders, followers and the situations (Spillane 2006). It tries to find out the interrelations of people and their situation through a wider lens where the individual knowledge and skill is measured as a matter of practice. The educational development purpose of a school is related to individual knowledge and learning which could be fulfilled through the practice of distributed leadership. Duignan (2006: 111) explains, 
Distributed leadership therefore must have a clear purpose and focus to bring about whole-school improvement in learning and teaching. In this way, distributing leadership can be an important motivator and a contributor to the quality of teaching and learning in the school and in the classroom.

In Bangladesh, the education sector is facing a challenging period for school leadership. There is much more concern about the quantitative issues, such as raising student enrolment, rather than quality improvement in terms of pedagogical development. It is now time to think about how the leadership of secondary schools could be developed to improve the quality of education in Bangladesh. The following discussion is about the execution of distributed leadership in terms of teacher and student improvement in the Bangladesh context.

\section{Distributed Leadership and Student Outcomes}

School leaders make significant difference to the institution and student outcomes. Much research show that school leadership produces different pictures of the effect of leadership on students' academic and social outcomes. Robinson (2008) states that to test the links between distributed leadership and student outcomes, researchers have to assess leaders' ability and work beyond measures of the nature and distribution of the leadership of professional development activities. It is necessary to know whether distributed leadership makes a difference in students' learning outcomes. Mulford's (2002) comprehensive study of leadership effects on student learning describes that, "student outcomes are more likely to improve when leadership sources are distributed throughout the school community and when teachers are empowered in areas of importance to them" (as cited in Harris 2008: 180).

School teachers in Bangladesh have little involvement in decision making and students are not involved in the process at all. As a result, teachers and students feel undervalued and excluded from the decision making process and have no stake in school development. Harris (2008: 180) notes that "Both teacher and student morale levels improved where teachers felt more included and involved in decision making related to the school development 
and change". Though there is little research to confirm any significant impact of distributed leadership on student achievement, the relationship is clear. Head teachers of secondary schools in Bangladesh should be encouraged to start the practice of this leadership that is based on collaboration and sharing to engage teachers more in school development with the aim of impacting on student achievement thus improving their schools.

\section{Distributed Leadership and Teacher Learning}

The school leaders in Bangladesh are not people-oriented. Due to their overstressed work and insufficient salary, they are always busy with their routine administration work and finding extra sources of income for the schools rather than to thinking about their professional development. As a result, the opportunity for organisational learning is hampered by overstress (Cardno 2002). Research shows that, successful leaders are people-centred who give importance to human needs rather than to organisational needs according to personal and professional values (Harris 2002).

It is important for visionary leaders to identify the goals of their school and to link them with teachers' professional development. According to Cardno (2002), the leader has to establish as a role model for openness to learning and have the capability to utilise the team strengths. Not only that, the teams in schools should be fostered by visionary leaders building the organisational climate rather than engaging in defensive communication. Leaders engage all the teachers in various responsibilities and activities thereby creating the prospect for them to be future leaders.

The effectiveness of schools depends on collective efforts of the teachers which help them to take up opportunities and gain leadership skills which build the leadership capacity of the school. Effective leadership is a collective endeavour which opens up the possibility to become leaders for all teachers (Harris 2002). This practice is hardly ever observed in Bangladesh. Teachers have little time to engage with leadership activities as they are busy with their routine work. Though sometimes they are interested and aware of some potential problems of their institution, the timeframe does not support them to get involved. Cardno (2002) notes that, workload 
has short time-frames for completion not allowing them to understand a problem deeply before moving on a solution. But it is essential to engage teachers to recognize and resolve the problems regarding school development in Bangladesh.

The over-stressed environment of schools does not support secondary school teachers to develop students and their schools in Bangladesh. If the situation is not supportive, the teachers may fail to do the job expected of them. According to Harris (2002), teachers cannot create and sustain conditions for productive development of students if those conditions do not exist for teachers in those schools. Teachers do not discuss and debate pedagogy with their colleagues because confidence is lacking. They always keep busy with their regular teaching and try to remain isolated so that others cannot find out their imperfections. To explain this, Cardno (2002) implies that, teachers' colleagues seldom challenge their behaviours as they are defensive about themselves. If they have the opportunity to learn from each other through distributed leadership, it is easy to develop themselves as well as their schools. The culture of helping each other facilitates team learning in schools. Learning outcomes of teams depend on the time-frame, cohesiveness in the team, client capacity and satisfaction, and openness to each other (Leithwood, Steinbach and Ryan 1997). Distributed leadership opens up the possibility for teachers to learn and use these factors among teachers for effective leadership in Bangladesh.

\section{Distributed Leadership and Teacher Development}

Leaders must carefully decide how teachers should engage in classroom practices. The classroom practices enhance leadership qualities to teachers when head teachers allocate some of their roles along. Leadership preparation should be integrated at different stages of professional careers using a wider range of learning strategies where experienced heads and principals could be the facilitators (Bush and Jackson 2002). Though some experienced school leaders in urban area distribute their leadership among different level of teachers, most of the rural schools do not practice it in Bangladesh. Distribution of leadership could reduce the job stress of a leader, if the teachers are skilled enough to do the recognized job. But Mayrowetz (2008) warns whether the practice

of distributed leadership can provide job assistance to over-stressed 
administrators; some researchers argue that it could be a risky business with the distribution of ineptitude.

To develop teachers as leaders, mentoring and coaching is needed in different levels of their professional life. In Bangladesh, though there is in-service and pre-service training for teachers, no leadership training is provided for the head teachers or general teachers. Mentoring and coaching for leadership development is well established in many countries through a number of ways including peer support, counselling, socialization and internship (Bush and Jackson 2002). In some cases, schools have the opportunity to engage teachers with leadership experience that adds to the capacity for decision making. Cardno's (2002) research shows that team members who engage in leadership activities are more accountable for decision making rather than just for their individual development as leaders. Recently, the Bangladesh government has taken an initiative to develop and deliver leadership training for the head teachers in secondary schools through Teachers Quality Improvement (TQI) project funded by ADB and CIDA (Ministry of Education 2010) which is a step in the right direction.

Professional commitment and job satisfaction are crucial factors in the success of every organization. Job satisfaction increases the dedication of professionals to fulfil the aims and objectives of the institute. Professional commitment is related to individual development as well as organizational success. Distributed leadership in schools fosters the professional commitment along with job satisfaction of staff. A positive correlation has been found between distributed leadership and teachers' self-efficacy and level of morale (Harris 2005). Distributed leadership is also considered as an essential element of high performance learning organizations.

\section{Distributed Leadership and Community}

Connection with community is important for successful leadership of schools since schools are considered to be social organizations. By establishing connections with community, leaders are able to gain greater access to the resources and to get support of that society for their school. As an external factor, community plays a vital role in school development. Leithwood, Steinbach and Ryan 
(1997) state that the external factors that influence team learning of a school positively or negatively are community, district, ministry, vision, culture and so on. Family and community are the sources of indigenous knowledge and the school would be enriched with social acquaintance by incorporating them into curriculum. Not only that, they also take part as important factors in decision making process of the school. Foster (2004) agrees that students and parents play a vital role in goal-setting and decision making of the school even though they are excluded from formal leadership.

Leaders can build strong connections among school, family and community by utilising the outside business of teaching and learning. Foster (2004) explains the advocacy role of schools as a place of connectivity as all the students and teachers go beyond formal divisions of grade and roles, and come together to work towards a common purpose of school improvement. Though there are managing committees in secondary schools in Bangladesh to engage community, they rarely consider the improvement of the school. When Foster (2004) implies that it is undoubtedly important for teachers, students and parents to have good working interrelationships to enhance a school's success, an opposite scenario presents the reality for leadership in secondary schools in Bangladesh.

\section{Patterns of Leadership Distribution}

School performance is affected by the patterns of leadership practice in schools. Leithwood, Strauss, Sacks, Memon and Yashkina (2006b) highlight two key conditions necessary for successful leadership distribution. First, leadership needs to be distributed to those who have, or can develop, the knowledge or expertise required to carry out the leadership tasks expected of them. Second, effective distributed leadership needs to be coordinated, preferably in some planned way. To distribute leadership, expertise in specific work is unlikely to be considered in Bangladeshi schools. Most of the time, personal relations with the head teacher or micro-politics between school and community become the basis of distribution.

Distributed leadership may be implemented in different ways. Gronn (2002) suggested three concretive forms of distributed leadership as: spontaneous collaboration, intuitive working 
relations, and institutionalized practice. Leithwood et al. (2006b) made some elaboration and refinement of them as: planned alignment, spontaneous alignment, spontaneous misalignment and anarchic misalignment. Though planned and spontaneous patterns of alignment have the maximum potential for short-term positive organizational change (Leithwood et al. 2006b), the spontaneous occurs more rather than the planned in Bangladesh.

\section{Impediments to Distributed Leadership}

There are several barriers to introduction and implementation of distributed leadership in Bangladesh. The teachers are not conscious enough of the concept and practice of distributed leadership. The traditional administrative structure of secondary schools and political environment put up barriers for that type of understanding. Harris (2005) points out that ignoring the major structural, cultural, and micro political barriers operating in schools makes distributed forms of leadership difficult to implement. The traditional hierarchy of leadership in schools in Bangladesh expects power in the top position to be that of the principal or head teacher. Sometimes the renegotiation of schools' roles may cause conflict and confusion about decision making which can create staff disappointment. Not only that, schools may face lack of competence of teachers to complete all sort of jobs skilfully. Timperley (2005) implies that the distribution of leadership among several people might result in the distribution of incompetence.

When incompetence in carrying out leadership tasks is an issue in distributing leadership in Bangladesh, educational expertise and building relationships with teachers are other important factors for leadership of head teachers to consider. If head teachers are not be able to develop a trust relation in the organization, they are unlikely to have significant outputs.

While educational expertise is a necessary condition for effective leadership, it is not sufficient; leaders must also build trust relationship if they are to engender and sustain improvements in teaching and learning. Leaders who show regards for others and treat them with respect, are seen by them as competent and having integrity, are trusted (Robinson, Hohepa and Lloyd 2009: 47). 
Head teachers in Bangladesh cannot build trust relationships easily due to lack of confidence or in relation to power practice. In some schools, which are operated by private sector, different scenarios might be seen according to power practices. The head teachers of those schools distribute their leadership in a planned way. As they are outside the boundary of straight government control and always thinking about the betterment of the schools, they often try to operate leadership in a diverse way. Sperandio (2005) explains the impact of social entrepreneurship to the educational leadership in Bangladesh in her study. She states that innovative leadership can progress the educational change in teaching methodology, administration and finance with the help of non-formal education sector. Consequently, building social networks and collaborating with commercial educational enterprises, the importance of networking and collaboration for small enterprises to increase their sustainability and access to resources are significant in Bangladesh. This evidence does not mean that all the private schools exercise innovative leadership such as distributed leadership. Though the disadvantages may have negative impact on implementing distributed leadership in Bangladesh, the benefits of it should be considered in a wider forum.

\section{Conclusion}

To develop and exercise distributed leadership in schools in Bangladesh, training programmes should be developed for head teachers and focused on long-term direction and change. Head teachers need to consider engaging teachers in decision-making process effectively so that they can use their expertise and can understand their fluid roles as teachers and leaders depending on the situation. Accordingly, head teachers should create opportunities for teachers to work alongside them to improve the leadership practices. They would have to build trust relationships with teachers and communities so that school improvement programmes can operate easily. Head teachers should be able to take on such initiatives. The Ministry of Education needs to develop new policy and direction aimed to give head teachers more responsibility for teacher professional development in their schools.

The Bangladesh government policies, in relation to operation of schools, define leadership as something an individual 
does, most specifically the head teacher's administrative job. It makes school leaders over-stressed and keep teachers away from leadership. However, as the First World is always keen to research and understand different principles and styles of leadership, it is imperative for Bangladesh to also understand leadership in diverse ways, not just as something performed by someone individually in a hierarchical structure. It may be that new and effective leadership concept of distributed leadership is desired and could evolve as less driven by individuals and more building a team approach.

Distributed leadership can create and offer opportunities of leadership activities for many of the school community to contribute to. This study considers only the possibilities and impediments regarding the implementation of distributed leadership in Bangladesh. Further research can follow that will examine different dimensions and forms of this leadership and its relation to school performance. This might be helpful for achieving the organizational learning and student outcomes that are needed in

Bangladesh. Such work may contribute in a broader way to specify a more favourable school leadership style in terms of social and economical conditions in Bangladesh.

\section{References}

Bangladesh Bureau of Educational Information and Statistics. 2007. Education System of Bangladesh. Dhaka: Ministry of Education.

Bangladesh Bureau of Educational Information and Statistics. 2010. Educational Structure of Bangladesh. Retrieved from http://www.banbeis.gov.bd/es_bd.htm

Bush, T., \& Jackson, D. 2002. A preparation for school leadership: International perspectives. Educational Management \& Administration, 30(4), 417-429.

Cardno, C. 2002. Team learning: opportunities and challenges for school leaders. School Leadership \& Management, 22(2), 211-223.

Duignan, P. 2006. Educational leadership: Key challenges and ethical tensions. New York: Cambridge University press.

Elmore, R. 2000. Building a New Structure for School Leadership. Washington, DC: The Albert Shanker Institute. 
Foster, R. 2004. Leadership and secondary school improvement: case studies of tensions and possibilities. International Journal of Leadership in Education, 8(1), 35-52.

Hargreaves, A. \& Fink, D. 2008. Distributed Leadership: democracy or delivery? Journal of Educational Administration, 46(2), 229-240.

Harris, A. 2008. Distributed leadership: according to the evidence. Journal of Educational Administration. 46 (2), 172-188.

Harris, A. 2005. Distributed leadership and school improvement: Leading or misleading? Journal of Curriculum Studies, 37, 255265.

Harris, A. 2002. Effective leadership in schools facing challenging contexts. School Leadership \& Management, 22(1), 15-26.

Harris, A., \& Muijs, D. 2005. Improving schools through teacher leadership. Berkshire, UK: Open University Press.

Leithwood, K., Mascall, B., Strauss, T., Sacks, R., Memon, N. and Yashkina, A. 2006 b. Distributing leadership to make schools smarter. Leadership and Policy, 6(1), 37-67.

Leithwood, K., Steinbach, R. \& Ryan, S. 1997. Leadership and team learning in secondary schools. School Leadership \& Management, 17(3), 303-325.

Mayrowetz, D. 2008. Making sense of distributed leadership: Exploring the multiple usages of the concept in the field. Educational Administration Quarterly, 44(3), 424-435.

Ministry of Education. 2010. Teaching Quality Improvement in Secondary Education Project, Retrieved from http://www.moedu.gov.bd/index.php?option=com_content $\&$ task $=v i$ ew\&id=352\&Itemid $=365$

Robinson, V., Hohepa, M., \& Lloyd, C. 2009. School Leadership and Student Outcomes: Identifying what works and why. Best evidence synthesis iteration. Wellington: Ministry of Education.

Robinson, V.M.J. 2008. Forging the links between distributed leadership and educational outcomes. Journal of Educational Administration, 46(2), 241-256. 
Sperandio, J. 2005. Social entrepreneurs and educational leadership in Bangladesh. Current Issues in Comparative Education, 8(1), 1830 .

Spillane, J.P. 2006. Distributed Leadership. San Francisco, CA: Jossey-Bass.

Thornton, H. 2006. Teachers Talking: the role of collaboration in secondary schools in Bangladesh. British Association for International and Comparative Education, 36(2), 181-196.

Timperley, H.S. 2005. Distributed leadership: Developing theory from practice. Journal of Curriculum Studies, 37, 395-420. 